\title{
20 DE NOVEMBRO EM CURITIBA ${ }^{1}$
}

\author{
Marco Aurélio Barbosa ${ }^{2}$
}

- Enviado em 09/03/2016

- Aprovado em 20/05/2016

\begin{abstract}
RESUMO
A pesquisa centrar-se-á em debates que envolvem a "negociação" em torno da Construção do Feriado do dia 20 de Novembro em Curitiba. A proposição desta data deu-se pelo "ativista e poeta negro Oliveira Silveira" na qual salienta a importância simbólica desta comemoração que, tem como centro a figura de Zumbi dos Palmares, símbolo de resistência e elemento referencial para o Movimento Negro e a população negra. Neste sentido, a pesquisa tem como ponto central os debates acerca da tentativa de efetivá-lo como feriado na cidade de Curitiba, que gerou intensa altercação sobre a legitimidade desta data, para a cidade. Tendo em vista a implementação deste pela Câmara dos Vereadores e Prefeitura de Curitiba, sendo comemorado pela primeira vez em 2013, e que após pressão da Associação Comercial do Paraná (ACP), acabou suspenso. Para tanto, utilizaram-se da via judicial, através de ação impetrada alegou prejuízo ao comércio da cidade, caso houvesse a parada, fato este que levou o judiciário a "cancelar" o feriado. Os diversos grupos que representam o movimento negro, entre outros, buscaram intervir, com objetivo de alterar a situação e para a manutenção do feriado, sendo contudo, derrotados, impedindo a comemoração efetiva da data, como fora proposta. Assim, a pesquisa buscará compreender como deu-se este evento, e como este afetou a população de Curitiba, os grupos de poder, as entidades ligadas direta e indiretamente ao movimento negro em sua busca pela implantação deste.
\end{abstract}

Palavras-chave: Consciência negra. Movimento Negro. Associação Comercial do Paraná. Racismo.

\section{LUTA PELO 20 DE NOVEMBRO EM CURITIBA}

No ano de 2013, foi decretado o Feriado da Consciência Negra em Curitiba, tendo como data comemorativa o dia Vinte de Novembro, entretanto, após forte pressão da Associação Comercial do Paraná (ACP) ${ }^{3}$, o mesmo foi suspenso. Para tanto, utilizaram-se da via judicial,

1 Uma versão preliminar desse trabalho foi apresentada no GT1: INSTITUIÇÕES E PODER: PARENTESCOS E GENEALOGIAS do VII Seminário Nacional de Sociologia e Política da UFPR realizado de 11 a 13 de maio de 2016 em Curitiba.

2 Graduado em Sociologia pela Universidade Federal do Paraná (UFPR); Graduado em História pelas Faculdades Integradas "Espírita” (UNIBEM); Especialista em Relações Étnico-raciais pelo Núcleo de Estudos AfroBrasileiro da Universidade Federal do Paraná (NEAB-UFPR); Mestrando em Sociologia pela Universidade Federal do Paraná (UFPR). Endereço eletrônico: barbosa.marco@gmail.com

3 É importante salientar aqui, que havia a presença de outro importante ator a SINDUSCON - Sindicato da Indústria da Construção Civil no Estado do Paraná - que junto a ACP trabalhou no sentido de impedir a adoção do feriado. 
através de ação impetrada alegando o enorme prejuízo ao comércio da cidade, caso houvesse a parada, fato este que levou o judiciário a "cancelar" o feriado.

Os diversos grupos que representam o movimento negro, o Sindicato dos Trabalhadores do Comércio de Curitiba, Vereadores e a Câmara Municipal de Curitiba, buscaram intervir, com objetivo de alterar a situação, fazendo mobilizações nas ruas e interpondo recursos junto ao judiciário, para a manutenção do feriado, sendo, contudo, derrotado nesta instância. Fato este que impediu a comemoração efetiva da data, como fora originalmente proposta.

Por conta deste fato, a ACP foi acusada de racismo, por parte do grupo derrotado, por impedir um feriado inédito, para este grupo. Assim, a pesquisa centrar-se-á nos debates que envolvem a "negociação" em torno da Construção do Feriado do dia 20 de Novembro em Curitiba, na qual se acha em jogo o Dia Consciência Negra, importante feriado para o Movimento Negro.

A proposição desta data em caráter nacional foi formulada pelo "ativista e poeta negro Oliveira Silveira"4, que a teria sugerido em oposição ao dia Treze de Maio, que é tido por este como uma falsa data comemorativa, visto que esta data já era contestada pelo próprio movimento negro, uma vez que, segundo Silveira (2003), o Treze de Maio não satisfazia, as necessidades do Movimento Negro e nem tão pouco anseios da população negra, sendo assim, portanto, "não havia por que comemorá-lo. A abolição só havia ocorrido no papel; a lei não determinara medidas concretas, práticas, palpáveis em favor do negro. E sem o treze era preciso buscar outras datas, era preciso retomar a história do Brasil" (SILVEIRA, 2003, p.18).

Neste sentido, Oliveira Silveira teria sugerido em oposição ao dia Treze de Maio, o Vinte de Novembro, onde justifica esta opção, apontando que:

Circulava na época o fascículo Zumbi, o $\mathrm{n}^{\circ} 6$ na série Grandes Personagens da Nossa História, da Abril Cultural. Essa publicação fortaleceu no frequentador Oliveira Silveira a ideia de que Palmares fosse a passagem mais marcante na história do negro no Brasil. Um século de liberdade e luta contra o escravismo imposto pelo poder colonial português era coisa muito significativa e animadora. E lá estava o dia 20 de novembro de 1695 , data da morte heroica de Zumbi, último rei e líder dos Palmares, marco assinalando também o final objetivo do Estado e país negro. (SILVEIRA,2003, p.25)

4 Oliveira Ferreira Silveira (1941-2009) foi um poeta brasileiro. Formou-se em Letras (Português e Francês) pela UFRGS. Militante do Movimento Negro em Porto Alegre, foi um dos fundadores do Grupo Palmares, sendo um dos líderes da campanha pelo reconhecimento do Dia da Consciência Negra em 20 de novembro. Disponível em http://www.palmares.gov.br/?p=31262. Acesso 13.março.2016. 
Salientando a importância simbólica desta comemoração que, tem como centro a figura histórica de Zumbi dos Palmares, marco da resistência e da luta em favor da igualdade. Assim, Zumbi é o principal elemento referencial para o Movimento Negro e a população negra enseja uma discussão sobre a importância deste como herói nacional negro, inclusive com a reivindicação da adoção de um feriado em sua homenagem.

Neste sentido, a pesquisa terá como ponto central os debates acerca da tentativa de efetivá-lo como feriado na cidade de Curitiba no ano de 2013, e que gerou intenso debate sobre a legitimidade, a necessidade e a importância desta data, para a cidade, uma vez que, esta é divulgada como "A Cidade Mais Europeia do Brasil", título que pode ter certa relevância simbólica, na negociação em torno da adoção do feriado. Moraes e Souza (1999), em seu artigo, "Invisibilidade, Preconceito e Violência Racial em Curitiba" fazem uma reflexão acerca da sub-representação do negro frente a outros grupos étnicos, mesmo minoritários, tendo em vista a sua representação negada frente a estes grupos, assevera que:

Mesmo que a população negra fosse uma "minoria", e esperamos ter demonstrado que não é assim, não seria motivo para ser esquecida. Ao contrário, dever-se-ia atentar para a criação de condições que alçassem esta população ao seu lugar de direito. Esta é a principal violência cometida contra este grupo e certamente a produtora e legitimadora de muitas outras. (MORAES e SOUZA, 1999, p.14)

Destarte, Moraes e Souza (1999), apontam que a suposta sub-representatividade étnica do negro, não deve se constituir como barreira à afirmação de qualquer grupo, sob risco de reforçar a exclusão e/ou ocultamento de certos grupos, entre outras questões.

Num primeiro momento busca-se identificar os atores do movimento negro de Curitiba, bem como, os da Associação Comercial do Paraná, e sua participação no que se refere as negociações em torno da adoção do feriado, onde cada qual busca impor seus interesses em torno deste, buscando averiguar a existência ou não de debates e pesquisas anteriores acerca deste debate, ampliando-as e atualizando-as, sem contudo limitar-se a análise dos movimentos sociais, mas, também dos grupos de interesse e as instituições envolvidas neste processo e os desdobramentos resultantes desta arguição. Para tanto parece lícito, lançar algumas indagações, tais como:

- De que forma um feriado negro poderia, se constituir em uma ameaça a ACP?

- O que se ganha e o que se perde, ou ainda, quem ganha e quem perde com o feriado e por que? 
- O que de fato está em jogo, seria apenas um interesse em torno de um suposto prejuízo causado por um dia de feriado?

- Quem são os agentes e instituições envolvidos neste debate e o que está em jogo?

- Quais os discursos mobilizados?

\section{CURITIBA ENTRE DOIS PROJETOS}

Ao observar a História Oficial do Brasil, o elemento negro na conjugação e construção de sua identidade desaparece como elemento constitutivo desta remetendo a invisibilidade do negro na sociedade brasileira. Segundo Leite (1996, p.46) não é que o negro não seja visto, mas sim que ele é visto como não existente:

a invisibilidade do negro é um dos suportes da ideologia do branqueamento, podendo ser identificada em diferentes tipos de práticas e representações. Ellison procura demonstrar que o mecanismo da invisibilidade se processa pela produção de um certo olhar que nega sua existência como forma de resolver a impossibilidade de bani-lo totalmente da sociedade.

Deste modo, olhar para o fenômeno da invisibilidade é compreender os modos e/ou mecanismos mobilizados para ocultar socialmente elementos "destoantes" de um projeto de cidade que se quer impor como verdade, no qual o debate acerca do feriado da Consciência Negra pode ser encarado como entrave. Neste sentido, Mário Antônio Sanches (1997), em sua dissertação de mestrado "O Negro em Curitiba: A invisibilidade Cultural do Visível", inicia seu debate tendo como fundo a festa que comemora o aniversário de 300 anos da cidade de Curitiba, dita como a festa das etnias, na qual os negros não se achavam representados, de modo que:

Durante os festejos do tricentenário, produz-se um discurso apresentando Curitiba como cidade de "primeiro mundo", "cidade europeia", e no qual os diferentes grupos étnicos de origem europeia são valorizados. Excluídos desse discurso que sinaliza uma "cidade de todas as gentes" os negros, principalmente aqueles que participam de movimentos sociais, procuram resgatar sua visibilidade e construir sua identidade de negros curitibanos. (SANCHES, 1997, p.1) 
Fato bastante curioso, já que em artigo de Jurandir de Souza (2011) intitulado "Espaço e territorialidade afro-descendente em Curitiba" ${ }^{5}$ o autor evidencia uma população negra, bastante significativa na composição da população curitibana aonde assevera que:

Segundo os dados oficiais, Curitiba e a Grande Curitiba compreendem 2,47 milhões de habitantes, divididos numa área de $432 \mathrm{~km}$ quadrados. No censo do IBGE de 2000, contavam com $22 \%$ de pessoas que se declararam negras. Este dado repercutiu positivamente no movimento negro, embora se acredite em um número mais elevado. Mesmo assim, reiterou o que muitos líderes do movimento negro local já haviam tomado como discurso, ou seja, sobre o alto número de afro-descendentes em Curitiba. (SOUZA, 2011, p.131)

Afirmação que de certo modo se opõe ao discurso de Wilson Martins ao descrever o Paraná da "trança loira" onde este se construiu "sem escravidão, sem negro, sem português e sem índio, dir-se-ia que a sua definição humana não é brasileira" (MARTINS, 1989, p.347). O discurso de Martins parece ter sido apropriado pela cidade portanto um projeto de feriado do Vinte de Novembro, da consciência negra, parece não fazer sentido.

No intuito de explicitar esse debate, se pesquisará junto à ACP e seus representantes, bem como, junto ao Movimento Negro e seus representantes, para se compreender como estes sujeitos colocam-se e mesmo observam os debates acerca do feriado, quais as estratégias adotadas pelos agentes ao tratar do tema em questão, no sentido de apreender o que está em jogo nesta disputa. A análise está amparada em parte em um enfoque comparativo, no qual buscará ver como outras cidades, como por exemplo São Paulo e Londrina se colocaram frente ao mesmo embate, que se fixará fundamentalmente na análise documental e revisões bibliográficas e entrevistas semiestruturadas com os sujeitos envolvidas neste debate, no intuito de perscrutar e validar, bem como, questionar os dados resultantes da pesquisa.

5 É importante salientar que o termo afro descendente é aqui utilizado para caracterizar as populações negras e /ou que partilhem deste fenótipo, ou seja, a população não branca que residente na cidade, isto é, a população negra ou mulata residente em Curitiba. 


\title{
REFERÊNCIAS
}

LEITE, Ilka B. Negros no sul do Brasil - invisibilidade e territorialidade. Santa Catarina: Letras Contemporâneas, 1996.

MARTINS, Wilson. Um Brasil diferente (ensaios sobre fenômenos de aculturação no Paraná). $2^{a}$ ed. São Paulo: TA. Queiroz, 1989.

PEREIRA, Magnus Roberto de Mello Semeando Iras Rumo ao Progresso: ordenamento jurídico e econômico da Sociedade Paranaense, 1829-1889. Curitiba, Ed. da UFPR, 1996.

MORAES, P. R. B. de \& Souza, M. G. Invisibilidade, preconceito e violência racial em Curitiba. Revista de Sociologia e Política. Curitiba: nº 13, Nov.1999.

SANCHES, M. A (1997). O negro em Curitiba: a invisibilidade cultural do visível. Curitiba: Universidade Federal do Paraná/Mestrado em Antropologia.

SILVEIRA, Oliveira (2003). Vinte de Novembro: história e conteúdo. In: SILVA, P. B. G.; SILVÉRIO, V. R (2003). Educação e ações afirmativas: entre a injustiça simbólica e a injustiça econômica. Brasília: Editora Inep: MEC, p. 21-42.

SOUZA, Jurandir (2011). Espaço e territorialidade afro-descendente em Curitiba In: COSTA, Hilton; SILVA, Paulo Vinicius B. (Orgs.). Notas de história e cultura afro-brasileiras. Ponta Grossa, Editora UEPG/ UFPR.

NOVEMBER 20th IN CURITIBA

\begin{abstract}
The research will focus on discussions involving "negotiations" around the holiday construction of 20 November in Curitiba. The proposition that date was given by "activist and black poet Oliveira Silveira" in which emphasizes the symbolic importance of this celebration that is centered around the figure of Zumbi dos Palmares, symbol of resistance and reference element for the black movement and the black population. In this sense, research has concentrated on the debates about the attempt to actualize it as a holiday in the city of Curitiba, which generated intense altercation about the legitimacy of this date, to the city. In view of the implementation of the City Council and City Hall of Curitiba, being celebrated for the first time in 2013, and that after pressure from the Paraná Trade Association (ACP), just suspended. Therefore, they used the courts, through action filed claiming injury to trade in the city, if there was a parade, a fact that led the court to "cancel" the holiday. The various groups representing the black movement, among others, sought to intervene in order to change the situation and for the holiday maintenance, and yet defeated, preventing the effective commemoration of the date, as had been proposed. Thus, the research will seek to understand how this event took place, and how this has affected the population of Curitiba, the groups of power, directly and indirectly related entities to the black movement in his quest for the implementation of this.
\end{abstract}

Key-words: Black Consciousness. Black Movement. Commercial Association of Paraná. Racism. 